\title{
Polypoid Barrett's High-Grade Dysplasia in a Patient with Familial Adenomatous Polyposis: a Unique Association
}

\section{H. C. Wolfsen}

Division of Gastroenterology and Hepatology, Mayo Clinic, Jacksonville, Florida, USA

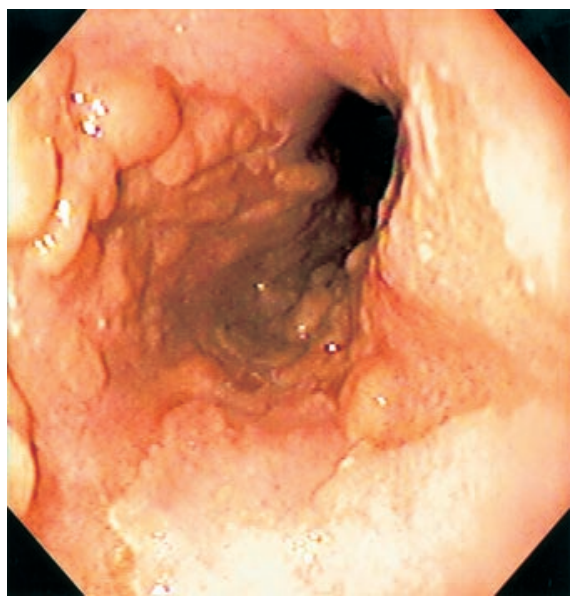

Figure 1 A 30-year-old white man with familial adenomatous polyposis (FAP) was referred for evaluation of Barrett's esophagus with high-grade dysplasia, an association not previously reported. Diagnosed during adolescence with FAP, he had undergone proctocolectomy in 1996. Subsequently, screening endoscopy for duodenal polyps detected longsegment Barrett's glandular mucosa replacing most of the esophageal mucosa $(14 \mathrm{~cm}$ segment length), with polypoid changes. Similarappearing polyps were noted throughout the stomach and duodenum.

\section{Corresponding Author}

\section{H. C. Wolfsen, M. D.}

Mayo Clinic

4500 San Pablo Road

Jacksonville, Florida 32224

USA

Fax: $\quad+1-904-953-7260$

E-mail: pdt@mayo.edu

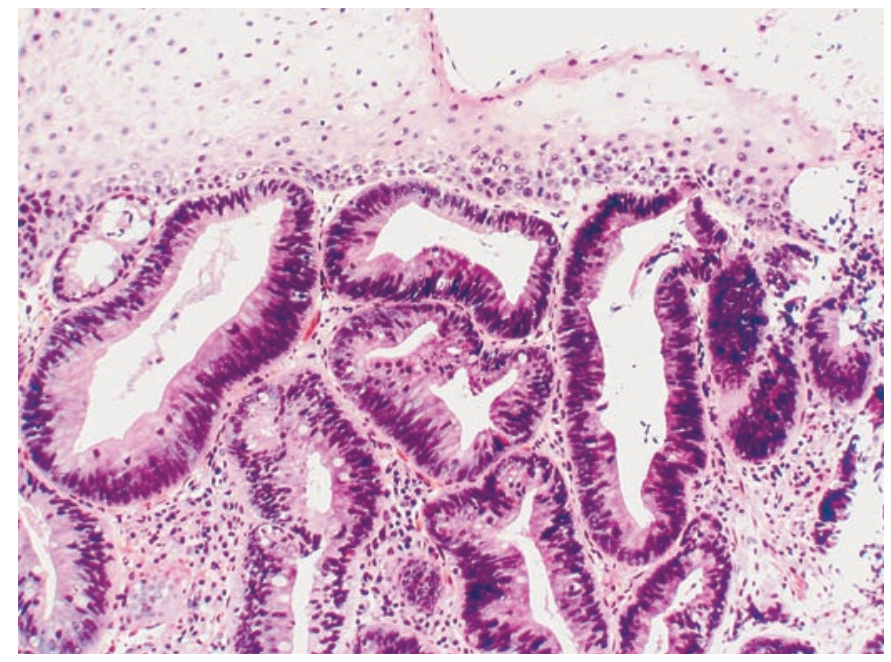

Figure 2 The histopathology section demonstrates overlying normal esophageal squamous mucosa, undermined by Barrett's glandular epithelium with high-grade dysplasia. The patient declined invasive treatment with porfimer sodium photodynamic therapy or esophageal resection. Medical therapy with a nonselective nonsteroidal anti-inflammatory drug, combined with highdose proton-pump inhibitor treatment, was initiated. 